\title{
ESTUDIOS CULTURALES Y LINGÜÍSTICOS CHINOS EN ESPAÑA
}

\author{
RUOJUN CHEN \\ Universidad de Lengua y Cultura de Pekín
}

J. A. Cervera, Tras el sueño de China. Agustinos y Dominicos en Asia Oriental a finales del siglo XVI, prólogo de Dolors Folch, Plaza y Valdés, Pozuelo de Alarcón/México, 2013, 537 págs.

J. J. Ciruela AlfÉrez (ed.), Aprender y enseñar chino. Jornadas académicas sobre la lengua china y su enseñanza, Universidad de Granada, 2013, 267 págs.

Los estudios sobre la lengua y cultura china en España son, o bien muy antiguos, o bien muy recientes. Como en otras esferas de la Comparatística, la cultura hispánica presenta aquí otra paradoja, que consiste fundamentalmente en la ruptura o discontinuidad con la tradición. Aplicada a los estudios sinológicos, la paradoja consiste en que en el contexto europeo y occidental España ha sido el primer y el último país en desarrollarlos. Los libros que vamos a comentar aquí vienen a aclarar $y$, en cierto modo, a solventar esa situación. Veamos cómo.

El profesor e investigador del Colegio de México, José Antonio Cervera, demuestra en Tras el sueño de China, que los religiosos agustinos y dominicos españoles de finales del siglo XVI fueron los pioneros en la transmisión del pensamiento chino a Europa. Los orígenes de la sinología española se remontan, ciertamente, a Martín de Rada y a Juan Cobo y a la denominada 
por José Eugenio Borao, «Escuela de traductores de Manila»1. El profesor Cervera es doctor en Ciencias Físicas por la Universidad de Zaragoza y en Estudios de Asia y África, especialidad China, por la Universidad Autónoma de México. En 2001 publicó en la universidad de Zaragoza la excelente monografía Ciencia misionera en Oriente, que presentaba los resultados de su Tesis Doctoral. Desde entonces, se ha consolidado como el principal estudioso en el ámbito hispanoamericano de la introducción de la ciencia europea en China, especialmente de las matemáticas y la astronomía. Como demuestra en Tras el sueño de China, en el último tercio del siglo XVI, Manila se convirtió en un puente entre Europa, América y Asia al conectar España, México y China, gracias a la legendaria ruta del Galeón de Manila. En esas primeras décadas de presencia española en las Filipinas, misioneros agustinos y dominicos intentaron penetrar en China. Fue en esa época cuando se dieron las primeras relaciones entre España y China, a través de México y de las Filipinas. Cervera explica que:

\begin{abstract}
China, por su grandeza y por las ideas que se tenían en Europa sobre su riqueza y cultura, era anhelada tanto por portugueses como por españoles. Estos últimos llegaron a Filipinas como etapa intermedia en su objetivo de establecerse en el continente, aunque posteriormente no pudieron llevar a cabo su deseo de crear un asentamiento permanente en China y las Filipinas se convirtieron en la colonia española en Asia Oriental durante varios siglos.
\end{abstract}

Junto con los primeros conquistadores y soldados, llegaron también los misioneros, que procedían de dos grupos principales: los miembros de la Compañía de Jesús y los religiosos dominicos, franciscanos y agustinos. Es cierto que los jesuitas fueron los más influyentes en la historia de las misiones en China, gracias a la política de acomodación diseñada por Alessandro Valignano, y que fue llevada a cabo, principalmente por Mateo Ricci. Los jesuitas idearon la sinización como estrategia para propagar la religión cristiana católica y encontraron en la ciencia la llave de entrada a China, influyendo directamente en las élites que controlaban el Imperio durante el siglo XVII fundamentalmente. Sin embargo, se olvida a menudo la contribución científica y sinológica de los religiosos de las llamadas órdenes mendicantes, que se dirigieron a China siguiendo la ruta española, esto es, cruzando el océano Atlántico hasta la Nueva España y desde allí a las islas Filipinas y en especial, de los dos más destacados, Martín de Rada (1533-1578) y Juan Cobo (?-1592), que fueron ayudados por la floreciente comunidad china de Manila, los llamados sangleyes del Parián. La primera expedición española a China fue llevada a cabo en 1575 por el agustino Martín de Rada, quien en una Relación de ese viaje, presentaba una información sistemática sobre China. Ese texto de Rada puede ser

\footnotetext{
${ }^{1}$ Véase J. E. Bora: «La "Escuela de traductores de Manila": Traducciones y traductores en la frontera cultural del Mar de China (Siglos XVI y XVII)», en I. Donoso Jiménez (ed.), Historia cultural de la lengua española en Filipinas: ayer y hoy, Verbum, Madrid, 2012, págs. 23-52.
} 
considerado el fundador de la sinología española. La otra gran figura intelectual es sin duda el dominico Juan Cobo, traductor del Beng Sim Po Cam (Mingsin Baojian, en transcripción Pinyin, Espejo rico del claro corazón), una compilación de máximas, proverbios y sentencias sapienciales de la antigua China cuyo manuscrito original se halla en la Biblioteca Nacional de Madrid, y que es el primer libro chino traducido a una lengua occidental. Para esta traducción Cobo fue ayudado por Juan Sami, un chino cristiano de Manila. La otra obra más importante de Cobo es el Shilu, la primera obra escrita en chino por un español, y uno de los primeros textos impresos en Filipinas, concretamente en 1593. El Shilu de Cobo es el segundo libro escrito en chino por un europeo, tras el Tianzhu Shilu de Ruggieri, publicado en 1584. Aunque, como sostiene Cervera Jiménez se puede considerar, en cierto modo, como una adaptación de la Introducción al Símbolo de la Fe, de fray Luis de Granada.

También se ocupa Cervera de las obras sobre China de otros agustinos y dominicos españoles. Entre ellos se encuentra la Historia del Gran Reino de la China (1585), de Juan González de Mendoza, quien nunca estuvo en China, y se basó en el Tractado em que se contam muito por estenso as cousas da China (1569) del dominico portugués Gaspar da Cruz y en el Discurso de la Navegación que los portugueses hacen a los Reinos y Provincias de Oriente, $y$ de la noticia que se tiene de las grandezas del Reino de la China (1577), Bernardino de Escalante, que constituye la primera descripción sobre China publicada en lengua castellana. Asimismo, González de Mendoza se basó en las mencionadas obras de Rada y de Cobo.

En resumen, se trata de una publicación importante que viene a culminar, en cierto modo, las investigaciones realizadas en ese campo de sinólogos como Dolors Folch y Manel Ollé, entre otros, y que permitirán reconstruir y desarrollar la historia de la sinología española.

Juan José Ciruela, lingüista y sinólogo de la Universidad de Granada, ha coordinado el volumen colectivo que lleva el título de Aprender y enseñar chino, que recoge las aportaciones de las primeras jornadas académicas sobre la lengua china y su enseñanza celebradas en dicha universidad en abril de 2011. El volumen inaugura la colección Confucio, dirigida por la sinóloga Alicia Relinque Eleta. La enseñanza del chino como lengua extranjera es, como señala el profesor Ciruela, una disciplina relativamente nueva del campo de la lingüística aplicada en China. En España, la Universidad Autónoma de Madrid, la Universidad Autónoma de Barcelona y la Universidad de Granada han sido las pioneras en la enseñanza del chino, que ha estado enmarcada en las Licenciaturas de Estudios de Asia Oriental (implantada en la UAM, la Universidad Popeu Fabra y la Universidad Oberta de Cataluña a partir de 2003) y la Licenciatura de Traducción e Interpretación, implantada en la década de los $90^{2}$. En ese contexto, la monografía que reseñamos

2 Véase Ma Querol Montaner: «Estudios sobre la lengua china en España», en M. A. Montaner Montava y M. Querol Bataller (coords.), Lenguas de Asia Oriental: Estudios lingüísticos y discursivos, Universidad de Valencia, 2010, págs. 43-88. 
constituye una aportación pionera, rigurosa e importante estructurada en diferentes ejes temáticos, que tratan las dificultades que plantean diversos aspectos y cuestiones didácticas de la enseñanza y el aprendizaje de la lengua china en el ámbito universitario español. Abre el volumen la contribución de la profesora Zhang Zhuo, del Instituto de Estudios Avanzados de chino en la Universidad de Lengua y Cultura de Pekín, sobre «La elaboración de ejercicios en los manuales de enseñanza del chino para extranjeros a la luz del modelo docente de asignación de tareas: el Manual de Chino Oral Intermedio como ejemplo» en su versión española y en el original chino, traducido por el profesor Ciruela. Basándose en los principios del modelo didáctico de asignación de tareas del Wei Yonghong en 2004, la profesora Zhang analiza los ejercicios de los materiales didácticos de dicho manual, señalando, en primer lugar, su problemática principal, que consiste en el desequilibrio de forma y significado en los ejercicios; en segundo lugar, muestra la insuficiencia de la interactividad y la necesidad de crear ejercicios en grupo y de carácter dialogado. Por último, concluye que «aunque existe una base teórica, sigue sin investigarse a fondo cómo el profesor debe controlar el grado de dificultad lingüística o manejar el tiempo, cuestiones que tienen que ver con la operatividad de la enseñanza y la valoración de los resultados». Consuelo Marco Martínez, profesora de la Universidad Complutense, dedica su extenso y prolijo artículo a «La enseñanza de "Chino para Hispanohablantes" dentro del Marco Común Europeo de Referencia». Se trata de una cuestión muy importante y necesaria para, por una parte, homogeneizar las programaciones en las universidades españolas y a su vez, de éstas con las universidades europeas. Por otra parte, para equiparar los niveles de los exámenes oficiales de lengua china (HSK) con los niveles de lengua establecidos en el marco europeo. También debe servir el contenido de ese artículo para contribuir a la programación y al desarrollo de la enseñanza de lengua y cultura china, en niveles básicos, intermedios y superiores en la propia Universidad Complutense. El profesor Ciruela Alférez aborda en «Análisis teórico y propuestas didácticas para la enseñanza de la lengua y la escritura chinas en el aula universitaria» la discusión de las cuestiones fonéticas y gramaticales más relevantes en el proceso de enseñar chino como lengua extranjera, haciendo especial hincapié en el aprendizaje de la escritura. Ciruela afirma que para los occidentales, cuyas lenguas han desarrollado escrituras alfabéticas, la dificultad fundamental a la hora de aprender chino, reside en la escritura. Para solventarla propone una enseñanza sistematizada e individualizada de la escritura china y la implantación de una asignatura específica de Escritura China, ya que «el estudio de los caracteres debe ser sistemático, escalonado y riguroso». Asimismo propone sensatas y útiles técnicas de enseñanza, tales como empezar por caracteres de fácil aprendizaje nemotécnico, apoyándose en tarjetas elaboradas por los propios estudiantes, utilizar todo tipo de juegos, y complementar la enseñanza con materiales informáticos y audiovisuales. María Querol, profesora de Lingüística en la Universidad Católica de Valencia, argumenta en «Gramática china. Nuevas perspectivas para su aprendizaje» la 
necesidad de incluir en el proceso de enseñanza la explicación de una terminología gramatical básica, y a ser posible, no especializada, que sea capaz de dar cuenta fehacientemente de las diferencias gramaticales entre el chino y el español. Propone y ejemplifica para la enseñanza de los contenidos gramaticales una serie de estrategias didácticas basadas en el uso de representaciones diagramáticas de las construcciones y diversas conceptualizaciones visuales de tipo cognitivo, «basadas en la identificación de las entidades en determinadas situaciones, junto con el papel y la función que en esta se les reconocen». El procedimiento consiste en, primero, la interpretación semántica $\mathrm{y}$, posteriormente, en una representación gráfica de dichas interpretaciones. Li Honying, profesor de la Universidad de Pekín, en «La inteligencia emocional como aspecto importante en el desarrollo profesional de los docentes de lengua china: análisis basado en la retroalimentación alumno-profesor», presentado en español y en chino, aborda la utilidad de la inteligencia emocional del profesor en la praxis docente del chino como lengua extranjera. Tras presentar una tipología del profesorado de chino como lengua extranjera, el profesor Li señala que:

[...] al final es siempre la mente del profesor y su inteligencia emocional en los que hay que apoyarse. Porque la enseñanza de lenguas es una actividad en la que toman parte «personas» y son las «personas» las que en el desarrollo de esta actividad juegan el papel más importante.

Por ello, concluye que «el docente de chino como lengua extranjera necesita desarrollar su profesión de forma autónoma y continua, necesita cultivar sin pausa su propia inteligencia emocional». Por su parte, Qiao Yun, profesora del Instituto Confucio de Granada, se centra en el artículo bilingüe «El aprendizaje y la enseñanza del vocabulario chino», y comenta diversas cuestiones de método y estrategia para responder a las preguntas «¿Qué debemos aprender del vocabulario chino» « ¿Cómo puedo aprender tantas palabras?». La profesora Qiao señala dos criterios, uno cuantitativo y otro cualitativo. El criterio cuantitativo tiene como objetivo el aprendizaje de 4000 a 10.000 palabras y el cualitativo consiste en aumentar el porcentaje de «palabras activas» en el vocabulario mental de los alumnos, para poder usarlas en la comunicación oral o en la expresión escrita, aprendiendo y dominando de forma sintética su forma, su pronunciación, su significado y su uso práctico. Sostiene que:

[...] para enseñar el vocabulario, el profesor debe seguir los siguientes pasos: presentación del vocabulario, enseñanza de la escritura y la pronunciación, paráfrasis y explicación con ejemplos, ampliación léxica gradual, ejercicios de vocabulario, dictado, expresarse utlizando oraciones y textos completos.

Cierra el volumen la contribución de Helena Casas-Tost, profesora de Traducción e Interpretación en la Universidad Autónoma de Barcelona, sobre 
«El desarrollo de la comprensión oral: una experiencia en la creación de materiales». La profesora Casas-Tost pone de relieve la falta de atención que la comprensión oral ha sufrido en los métodos tradicionales de chino y presenta los resultados de un proyecto de la Escuela Oficial de Idiomas de Barcelona-Drassanes para el fomento de la comprensión oral aplicado a la lengua china, en el Marco Común Europeo de Referencia para las Lenguas. La creación de nuevos materiales para fomentar la comprensión oral en chino se sustenta en dicho proyecto en tres pilares: el uso de materiales auténticos, la sencillez de diseño y facilidad de uso y el fomento de la autonomía de los estudiantes. Los materiales audiovisuales usados han sido: anuncios, noticias, documentales, programas de televisión de entretenimiento, programas educativos de televisión, dibujos animados, entrevistas, etc. Tras presentar un análisis cualitativo de la experiencia didáctica basado en la valoración de la misma por estudiantes y profesores que han participado en ella, señala la conveniencia de abordar en el futuro un análisis cuantitativo y finalmente, considera que dicha experiencia «podría ser el punto de partida para elaborar una base de datos de materiales didácticos de chino a partir de documentos audiovisuales auténticos».

En definitiva, nos encontramos ante un volumen colectivo lleno de ideas sugerentes y proyectos valiosos para hacer avanzar la didáctica de la lengua china para extranjeros. Sería deseable que la Universidad de Granada continuara en los próximos años con esta espléndida, innovadora y utilísima iniciativa, y que su labor se viera acompañada de iniciativas similares en otras universidades, institutos y centros donde se enseña la lengua china en España. 